\title{
Yetişkin Bireylerin Diş Macunu Seçim Kriterlerinin İncelenmesi
}

\author{
Investigation of Toothpaste Selection Criteria of Adults
}

\author{
Merve Köseoğlu' ${ }^{1}$, Tugba Ayhanci², Elif Tuğçe Nacar ${ }^{3}$, Aysu Kelle ${ }^{3}$, Hacer Coşkun ${ }^{3}$, \\ Melike Akyol ${ }^{3}$, Mine Keskin ${ }^{4}$, Selma Altındiş ${ }^{5}$ \\ ${ }^{1}$ Sakarya Üniversitesi, Diş Hekimliği Fakültesi, Protetik Diş Tedavisi AD, Sakarya,Türkiye \\ ${ }^{2}$ Sakarya Üniversitesi, Tip Fakültesi, Tibbi Mikrobiyoloji AD Sakarya,Türkiye \\ ${ }^{3}$ Sakarya Üniversitesi, Diş Hekimliği Fakültesi, 1. Sınıf Öğrencisi Sakarya,Türkiye \\ ${ }^{4}$ Sakarya Üniversitesi, Tip Fakültesi, Halk Sağı̆̆̆ AD Sakarya,Türkiye \\ ${ }^{5}$ Sakarya Üniversitesi, İşletme Fakültesi, Sağlık Yönetimi AD Sakarya,Türkiye
}

ORCİD

Merve Köseoğlu: https://orcid.org/0000-0001-9110-9586

Tuğba Ayhanc1: https://orcid.org/: 0000-0002-2115-6261

Elif Tuğçe Nacar: https://orcid.org/0000-0002-1423-5738

Aysu Kelle: https://orcid.org/0000-0001-9016-8744
Hacer Coşkun: https://orcid.org/0000-0003-0396-3083 Melike Akyol: https://orcid.org/0000-0002-4201-4318

Mine Keskin: https://orcid.org/0000-0003-0238-1735

Selma Altındiș: https://orcid.org/0000-0003-2805-5516

\author{
Yazış̧ma Adresi / Correspondence: \\ Merve Köseoğlu \\ Mithatpaşa Mah. Adnan Menderes Cad. No:122/B Adapazar/Sakarya \\ T: +9026429541 17 E-mail: mervekoseoglu89@gmail.com
}

Geliş Tarihi / Received : 11-06-2019 Kabul Tarihi / Accepted : 16-07-2019 Yayın Tarihi / Online Published: 29-08-2019

Köseoğlu M., Ayhancı T., Nacar E.T., Kelle A., Coşkun H., Akyol M., Keskin M., Altındiş S.,

Yetişkin Bireylerin Diş Macunu Seçim Kriterlerinin İncelenmesi ,

J Biotechnol and Strategic Health Res. 2019;3(2):91-95 DOİ:10.34084/bshr.575466

\footnotetext{
Öz

Amaç Bu çalışmanın amacı, yetişkin bireylerin diş macunu seçiminde etkili olan faktörleri araştırmaktır.

Gereç ve Araştırma, Türkiye genelinde, 251 yetişkin bireyin katılımı ile gerçekleștirilmiştir. Çalışma kapsamında bireylere 17 sorudan oluşan bir web anket uygulanmıștır. Yöntemler Çalışmadan elde edilen verilen istatistiksel analizi, SPSS 23,0 (SPSS Inc., Chicago, IL, ABD) programı kullanılarak yapıllmıștır. Verilerin analizinde, tanımlayıcı istatistikler ve ki-kare testi uygulanmıștır. İstatistiksel anlamlılık düzeyi $\mathrm{p}<0,05$ olarak belirlenmiștir.

Bulgular Calıșmanın sonuçlarına göre, diș hekiminin tavsiyesinin, televizyon ve internet reklamlarının, ambalajının, köpürme miktarının, diș fırçasıyla aynı marka olmasının bireylerin diș macunu seçiminde hiçbir zaman etkili olmadığı belirlenmiștir. Ancak, diş macununun beyazlatma veya hassasiyet giderici özelliği olmasının, diș macunu seçiminde sıklıkla etkili olduğu anlaşılmıștır. Katılımcıların çoğunluğu, diş macununu bazen arkadaşlarının veya ailesinin önerisiyle seçtiğini ( $\mathrm{p}=0,26)$ ve diş macunu alırken ekonomik olmasına özen gösterdiklerini $(\mathrm{p}=0,37)$, diş macununun kokusunun $(\mathrm{p}=0,37)$ ve köpürme miktarının ( $\mathrm{p}=0,39)$ diş macunu seçimini etkilediğini bildirmișlerdir.

Sonuç Farklı sosyodemografik özelliklere sahip bireylerin diș macunu tercihleri de farklılık göstermektedir. Diș macunu seçimlerinde ürünün tadı, kokusu, içeriği, fiyatı, ambalajı, ulaşılabilirliği, belirli bir marka olması, tv ve internet reklamları, diş hekiminin veya çevresindeki kişilerin tavsiyesi ve bireyin sosyodemografik özellikleri ve alışkanlıkları etkili olmaya devam etmektedir.

Anahtar Diş Macunu, Seçim nedenleri, Sosyodemografik özellikler

Kelimeler

Abstract

Objective The aim of this study was to investigate the factors affecting the choice of toothpaste in adult individuals.

Materials and This research, in Turkey, was held with the participation of 251 adult people. A web questionnaire consisting of 17 questions was applied to the individuals. The statistical analysis obtained

Methods from the study was performed using SPSS 23.0 (SPSS Inc., Chicago, IL, USA) program. In the analysis of the data, descriptive statistics and chi-square test were applied. The level of statistical significance was set at $p<0,05$.

Results According to the results of the study, the recommendation of the dentist, television and internet advertisements, packaging, amount of foaming, being the same brand as the toothbrush were determined to be never effective in the selection of toothpaste. However, it has been found that whitening or desensitizing properties of toothpaste are often effective in toothpaste selection. The majority of the participants stated that they sometimes chose toothpaste with the recommendation of friends or family $(p=0,26)$ and they took care to be economical when buying toothpaste $(p=0,37)$, the smell of toothpaste $(p=037)$ and the amount of foaming $(p=0,39)$.

Conclusion Toothpaste preferences of individuals with different sociodemographic characteristics differ. The taste, smell, content, price, packaging, accessibility, being a certain brand, TV and internet advertisements, the advice of the dentist or the people around him and the sociodemographic characteristics and habits of the individual continue to be effective in the selection of toothpaste.

Keywords Toothpaste, Reasons for Selection, Sociodemographic characteristics
} 


\section{GIIRIŞ}

Toplum ağız diş sağlı̆̆ını en çok etkileyen problemlerden olan diş çürügü ve dişeti hastalıklarının önlenmesinde, mikrobiyal dental plağın dişler üzerinden uzaklaştırılması kritik öneme sahiptir. ${ }^{1,2}$ Oral hijyenin sağlanmasında en önemli yöntem ise dişlerin günde 2 kere florid içeren macunla firçalanmasıdır. ${ }^{3,4}$

Kozmetik etki sağlamak ve ağza güzel tat vermek amacıyla geliştirilen diş macunları, rutin ağız bakımında kullanılan en etkili terapötik ve kozmetik ajanlardandır. Diş macunları ayrıca, rutinde en yaygın olarak kullanılan dental ürünlerdendir. ${ }^{5}$

Diş macunlarının içeriğinde bulunan elemanlar aşındırıcılar, su, nemlendiriciler, deterjanlar, bağlayıcı ajanlar, tatlandırıcılar, terapötik ajanlar, renklendiriciler ve koruyucular bulunmaktadır. ${ }^{5}$ Diş macunlarının yapısındaki terapötik ajanlar; plak oluşumunu önleyen, antibakteriyel özelliğe sahip, çürük önleyici ajanlar, diş taşı oluşumunu azaltıcı ajanlar, diş hassasiyetini giderici ajanlar ve beyazlatıcı ajanlardır. ${ }^{6}$

Florid içeren diş macunları ile diş fırçalama, diş çürüklerinin önlenmesinde çok eskiye dayanan bir yöntemdir. Ticari diş macunlarının büyük bir kısmında florid tek başına veya birleşik halinde (sodyum monoflorofosfat, sodyum florid, kalay florid, amin florid vs.) kullanılır.,

Diş macunu seçimi bireyler arasında farklılık gösterebilmektedir. Bu durum, bireyin sosyoekonomik durumu, ürünün bireyin çevresindeki kişiler veya diş hekimleri tarafından önerilmesi, tv ve internet reklamları, diş macununun ambalajı, tadı, kokusu, içeriği gibi faktörlerden etkilenmektedir. ${ }^{9,10}$

Literatürde bireylerin diş macunu seçim kriterlerini inceleyen çalışmalar mevcuttur. ${ }^{11-15}$ Ancak Türk popülasyonunda, bireylerin diş macunu seçimlerini detaylı olarak inceleyen güncel bir çalışmaya rastlanamamıştır.
Bu çalışmanın amacı, Türkiye'de yaşayan yetişkin bireylerin rutinde kullandıkları diş macunlarını seçiminde etkili olan faktörleri araştırmaktır. Çalışmanın hipotezi ise, farklı sosyodemografik özelliklere sahip kişiler arasında, diş macunu seçim kriterlerinin farklılık gösterebileceğidir.

\section{GEREÇ ve YÖNTEM}

Araştırma, yetişkin bireylerin diş macunu seçim kriterlerini belirlemeye yönelik kesitsel tipte tanımlayıcı araştırmadır. Sakarya Üniversitesi Tip Fakültesi'nden 7152473/050.01.04/209 nolu etik kurul onayı alınarak çalışmaya başlanmıştır. Anket çalışması, Kasım- Aralık 2018 tarihleri arasında, Türkiye genelinde, 251 kişinin katılımı ile gerçekleştirilmiştir. Anket sorularını uygulamadan önce, çalışmaya katılan kişilerden bilgilendirilmiş olur formu alınmıştır.

Çalışma kapsamında bireylere, literatürden yararlanılarak oluşturulan11-15 ve 17 sorudan oluşan bir anket uygulanmıştır. Çalışmaya katılan bireylerden, anket sorularını bireysel ve gönüllü olarak cevaplamaları istenmiştir.

Çalışmadan elde edilen verilen istatistiksel analizi, SPSS 23,0 (SPSS Inc., Chicago, IL, ABD) programı kullanılarak yapılmıştır. Tanımlayıcı istatistiklerin sonuçları, sayı ve yüzde olarak verilmiş ve gruplar arası farklılıkları karşılaştırmak için ki-kare testi uygulanmıştır. İstatistiksel anlamlılık düzeyi $\mathrm{p}<0,05$ olarak belirlenmiştir.

\section{SONUÇ}

Anket sonuçları değerlendirildiğinde, çalışmaya katılan bireylerin büyük bir çoğunluğunun $(\% 59,8)$ 18-25 yaş aras1, kadın (\%63,3), 1800 tl'den az gelire sahip $(\% 61,4)$, öğrenci (\%51) ve eğitim düzeylerinin üniversite $(\% 51,4)$ olduğu belirlenmiştir (Tablo 1). 


\begin{tabular}{|c|c|c|c|}
\hline Yaş arahăġ (yıl) & "n (\%) & Cinsiyet & "n \\
\hline $18-24$ & $150 \quad(59,8)$ & Kadin & $155 \quad(63,3)$ \\
\hline 25-34 & $52 \quad(20,7)$ & Erkek & $(36,7)$ \\
\hline $35-44$ & $(12,0)$ & Ayhk geliri & (9) \\
\hline $45-54$ & $(4,00)$ & $0-2000$ \&l & $148 \quad(61,4)$ \\
\hline $55-65$ & $(2,4)$ & $2001-3000 \mathrm{tl}$ & $45 \quad(18,7)$ \\
\hline 65 yaş ûstũ & $(0,8)$ & $3001-5000 \mathrm{tl}$ & $(15,4)$ \\
\hline Egitim durumu & "n (\%) & $5001-10000$ tl & $(2,5)$ \\
\hline Okuryazar & $(0,0)$ & 10000 tl üzeri & $(2,1)$ \\
\hline filkokul & $(6,8)$ & Meslegi & (\%) \\
\hline Ortaögretim & $(5,2)$ & Ōgrenci & $128 \quad(51,0)$ \\
\hline Lise & $46 \quad(18,5)$ & Ōgretim ũyesi & $1 \quad(0,4)$ \\
\hline Universite & $128(51,4)$ & Ev hanımı & $(9,2)$ \\
\hline Yũ̄ssek lisans & $19 \quad(7,6)$ & Ōzel sektōr & $(16,7)$ \\
\hline \multirow[t]{4}{*}{ Doktora } & $(2,4)$ & Kamu sektôrrū & $(12,7)$ \\
\hline & & Emekli & $(1,2)$ \\
\hline & & Çalışmıyor & $(4,0)$ \\
\hline & & Diger & $(4,8)$ \\
\hline
\end{tabular}

Tablo 1. Çalışmaya katılan bireylerin sosyodemografik özellikler

Çalışmaya katılan bireylerin büyük bir çoğunluğu, diş macununu hiçbir zaman diş hekiminin tavsiyesi üzerine $(\mathrm{p}=0,17)$ veya televizyon ve internet reklamlarında gördükleri arasından seçmediklerini ( $\mathrm{p}=0,33)$, diş macununun ambalajının seçimlerini etkilemediklerini $(\mathrm{p}=0,21)$, diş macununun diş fırçasıyla aynı marka olmasına dikkat etmediklerini $(\mathrm{p} \bowtie 0,01)$ belirtmişlerdir. Katılımcıların çoğunluğu, diş macununu bazen arkadaşlarının veya ailesinin önerisiyle seçtiğini $(\mathrm{p}=0,26)$ ve diş macunu alırken ekonomik olmasına özen gösterdiklerini $(\mathrm{p}=0,37)$, diş macununun kokusu $(\mathrm{p}=0,37)$ ve köpürme miktarı $(\mathrm{p}=0,39)$ seçimini etkilediğini bildirmişlerdir. Bireylerin çoğunluğu sıklıkla, diş macununun ağızda tat bırakmas1nın seçimlerini etkilediğini $(\mathrm{p}=0,42)$, üretici firma tarafından beyazlatma $(\mathrm{p}=0,29)$ veya hassasiyet giderici $(\mathrm{p}=0,33)$ özelliği olduğu söylenen diş macunlarını tercih ettiklerini belirtmişlerdir. Bireylerin floridli diş macunlarını tercih yüzdeleri arasında ise istatistiksel olarak anlamlı bir fark bulunamamıştır ( $\mathrm{p}=0,07)$ (Tablo 2).

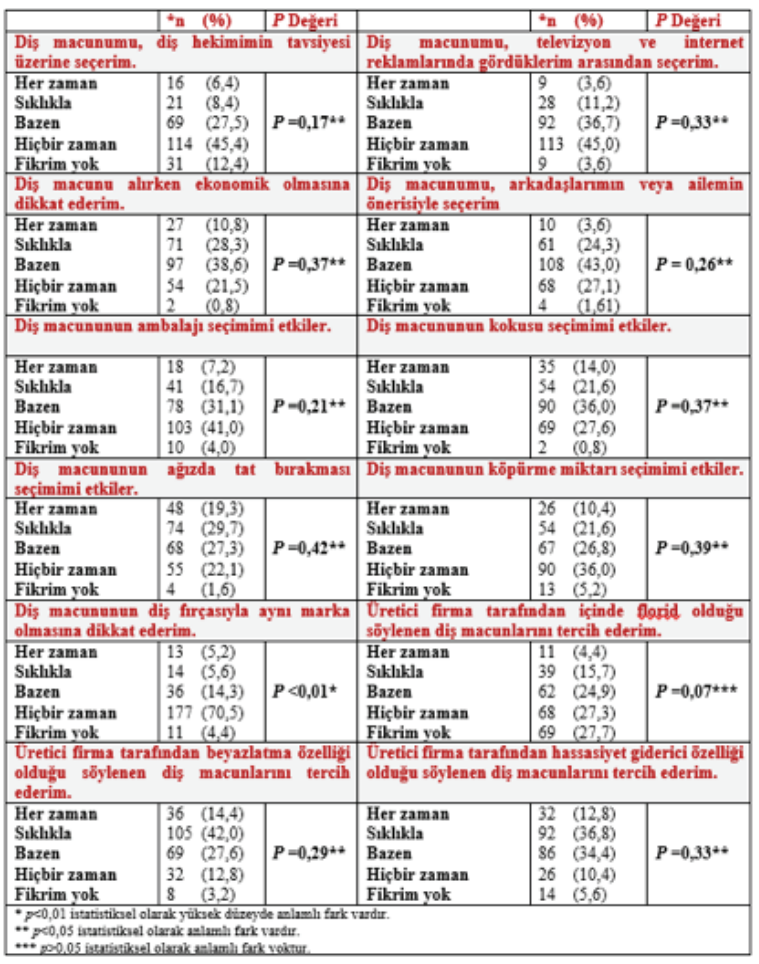

Tablo 2. Bireylerin diş macunu seçimlerinde etkili olan faktörler

Çalışmanın sonuçları, bireylerin farklı sosyodemografik özelliklerine göre değerlendirildiğinde; kadın, 18-25 arası, öğrenci, eğitim durumu üniversite olan ve 0-1800 tl gelire sahip olan bireylerin, diğer gruplara göre diş macunu seçiminde, macunun tadının ( $\mathrm{p}=0,23)$, beyazlatma $(\mathrm{p}=0,18)$ ve hassasiyet giderici etkisinin $(\mathrm{p}=0,29)$ daha fazla etkili olduğu belirlenmiştir.

\section{TARTIȘMA}

AğıZ sağlığının devamında, ağız hijyeninin sağlanması son derece önemlidir. İyi bir ağız hijyeni ise, dişlerin diş macunu, diş fırçası ve ara yüz bakım gereçleriyle düzenli olarak temizlenmesiyle sağlanabilir. ${ }^{16}$ Ağız diş bakımında kullanılan diş macunlarının seçimleri bireyler arasında farklılık göstermektedir., ${ }^{910}$

Çalışmamızda Türkiye' de yaşayan bireylerin diş macunu seçim kriterleri incelenmiş ve çalışmamızın sonucuna 
göre, diş macunu seçimi, bireylerin yaşları, eğitim durumları ve gelir düzeylerine göre farklılık gösterdiğinden hipotezimiz kabul edilmiştir.

Literatürde diş macunu seçimi ile ilgili farklı çalışmalarda, farklı sonuçlar elde edilmiştir. ${ }^{11-15}$ Opeodu ve ark. ${ }^{11}$ çalışmalarında Nijerya' da diş hekimine başvuran 202 kişinin büyük bir çoğunluğunun yalnızca belli bir marka diş macunu tükettiklerini, diş macununu seçerken tadından, florid içeriğinden, diş macunuyla ilgili önceki deneyiminden ve diş hekimi tarafından önerilmesinden etkilendiklerini; diş macunu ambalajından, medya reklamlarından, bitkisel içeriğinden, aile tavsiyesinden etkilenmediklerini belirtmişlerdir.

Umanah ve ark. ${ }^{12}$ çalışmalarında Nijerya' da 16-36 yaş arasındaki 150 öğrencinin diş macunu seçimini belirleyen faktörlerden en önemlisinin fiyatı olduğunu, diğer faktörlerin ise macunun tadı, florid içeriği, televizyon ve internet reklamları olduğunu bildirmişlerdir.

Kote ve ark. ${ }^{13}$ Hindistan'da yaşayan 1224 öğrenci arasında yaptıkları çalışmada, diş macunu seçiminde en etkili faktörün diş hekimi tavsiyesi, diğer faktörlerin ise diş macununun tadı ve kokusu, rengi, aile/arkadaş tavsiyesi ve ürün reklamı olduğu, en az etkili faktörün ise diş macununun fiyatı olduğunu belirtmişlerdir.

Vani ve ark. ${ }^{14}$ Hindistan'daki Bangalore şehrinde yaşayan 200 kişinin diş macunu seçiminde diş hekiminin tavsiyesi, macunun belirli bir marka olması, kalitesi, tadı, fiyatı, ulaşılabilirliği, ambalajı, diş macununun beyazlatıcı, hassasiyet giderici ve çürük önleyici özelliğinin olmasının etkili olduğunu bildirmişlerdir.

Derakhshi1 $^{5}$ ise Türkiye'de 100 kişinin katılımıyla gerçekleştirdiği çalışmada, bireylerin diş macunu alırken etkilendikleri faktörleri, tavsiye, reklam, kolay ulaşılabilirlik, paket tasarımı olarak belirlemiştir. Ayrıca, katılımcıların büyük bir çoğunluğu diş macununun popülerliğinin, fi- yatının, ambalaj tasarımının, macunu satın almalarında etkili olduğunu belirtmişlerdir.

Türkiye' de yaşayan 251 yetişkinin katılımıyla gerçekleştirilen mevcut çalışmanın sonuçlarına göre, diş hekiminin tavsiyesi, televizyon ve internet reklamları, ambalajı, köpürme miktarı, diş fırçasıyla aynı marka olması bireylerin diş macunu seçiminde hiçbir zaman etkili değildir. Ancak, diş macununun beyazlatma veya hassasiyet giderici özelliği olması, diş macunu seçiminde sıklıkla etkilidir. Diş macununun kokusu, ekonomik olması, arkadaş veya aile tarafından önerilmesi, diş macunu seçiminde bazen etkilidir. Literatürdeki çalışmaların ${ }^{11-15}$ sonuçlarının birbirlerinden ve mevcut çalışmanın sonuçlarından farklılık göstermesinin, çalışmalardaki popülasyonların farklı olmasından kaynaklandığı düşünülmektedir.

Sonuç olarak, farklı çalışmalar, bireylerin kullandıkları diş macunlarını seçimlerinde ürünün tadı, kokusu, içeriği, fiyatı, ambalajı, ulaşılabilirliği, belirli bir marka olması, tv ve internet reklamları, diş hekiminin veya çevresindeki kişilerin tavsiyesinin ve bireyin sosyodemografik özelliklerinin etkili olabileceğini göstermektedir. 
Journal of BSHR 2019;3(2):91-95

\section{Kaynaklar}

1. Nakonieczna-Rudnicka M, Bachanek T, Strycharz-Dudziak M, et al. Oral hygiene habits among tobacco-smoking and nonsmoking students of the Medical University of Lublin chosen aspects. Przegl Lek 2010;67(10):871-874.

2. Suomi, JD. The effect of controlled oral hygiene procedures on the progression of periodontal disease in adults results after two years. J Periodontol 1969; 40(7):416-420.

3. Creeth JE, Gallagher A, Sowinski J, et al. The effect of brushing time and dentifrice on dental plaque removal in vivo. J Dent Hyg 2009;83(3):111-116.

4. Lindenmüller H, Lambrecht JT. Oral care. Curr Probl Dermatol 2011;40(1):107-115.

5. Harris NO, Garcia-Godoy F. Primary preventive dentistry. 6th ed. Upper Saddle River, NJ: Pearson Education, 2004.

6. Forward GC, James AH, Barnett P, et al. Gum health product formulations: what is in them and why? Periodontol 2000 1997;15(1):32-39.

7. Andersson M, Hindsén M. Rhinitis because of toothpaste and other menthol-containing products. Allergy 2007;62(3):336-337.

8. Reynolds EC, Cai F, Cochrane NJ, et al. Fluoride and casein phosphopeptide-amorphous calcium phosphate. J Dental Res 2008; 87(4):344-348.

9. Paik DI, Moon HS, Horowitz AM, et al. Knowledge of and practices related to caries prevention among Koreans. J Public Health Dent 1994;54(4):205-210.
10. Sarker S, Yousuf S, Monzoor MZ. Influences on brand selection decisions of staple goods: A study on toothpaste users of Khulna city. J World Econ Res 2013;2:58-66.

11. Opeodu OI, Gbadebo SO. Factors influencing choice of oral hygiene products by dental patients in a Nigerian teaching hospital. Ann Ibd Pg Med 2017;15(1):51-56.

12. Umanah $A U$, Braimoh $O B$. Oral hygiene practices and factors influencing the choice of oral hygiene materials among undergraduate students at the University of Port Harcourt, Rivers State, Nigeria. J Dent Allied Sci 2017;6(1):3-7.

13. Kote S, Dadu M, Sowmya AR, et al. Knowledge, attitude and behaviour for choosing oral hygiene aids among students of management institutes, Ghaziabad, India. West Indian Med J 2013;62(8):758-763.

14. Vani G, Babu MG, Panchanatham N. Toothpaste brands - A study of consumer behaviour in Bangalore city. J Econ Behavioral Stud 2010;1(1):27-39.

15. Derakhshi, Arvin. Markanın Tüketici Davranıslarına Etkisi: Dis Macunu Sektörü Üzerine Bir İnceleme, Yüksek Lisans Tezi, İstanbul Aydın Üniversitesi Sosyal Bilimler Enstitüsü, 2017.

16. Rimondini L, Zolfanelli B, Bernardi $F$, et al. Self-preventive oral behavior in an Italian university student population. J Clin Periodontol 2001;28(3):207-211. 